\title{
Parity as a correlate of adult female urinary incontinence prevalence
}

\author{
Anders Foldspang, Søren Mommsen, Gitte Wrist Lam, Lisbeth Elving
}

\begin{abstract}
Study objective-The aim was to investigate the possible association between parity, as indicated by the number of childbirths, and prevalence of urinary incontinence in an adult female population sample.

Design and setting-A sample of 3114 women aged 30-59 years was selected at random from the population of Aarhus, Denmark, and mailed a self administered questionnaire on urinary incontinence and, among other things, parity.

Participants-A total of 2631 questionnaires was returned $(85 \%)$ with a slight but significant decrease in respondency by age.

Main results-The 1987 urinary incontinence period prevalence was $17 \%$. Seventy eight percent were parous, and $24 \%$ had had three or more childbirths. In women aged 30-44 years, the prevalence of urinary incontinence was found to be associated with parity and, in women aged 45 years and more, with three or more childbirths. In parous women $30-44$ years of age, the prevalence of urinary incontinence increased with age at last childbirth and, in women aged 45 years and over, it increased with increasing parity but decreased with increasing age at first childbirth. In parous women, no association was found with time since last childbirth. Among clinical types of urinary incontinence, stress incontinence consistently showed the strongest associations with indicators of parity. In women aged 30-44 years, nearly two thirds of the 1987 prevalence of stress incontinence could be attributed to parity.
\end{abstract}

Conclusions-These findings support the hypothesis that pregnancy and childbirth are potent causes of female urinary incontinence, so that they exert considerable impact on the level of population urinary incontinence prevalence. In the individual woman, the effect seems to be cumulative and long lasting but fades with age.

f Epidemiol Community Health 1992; 46: 595-600

The experience of episodes of urinary incontinence, involuntary loss of urine, seems to be a condition prevalent not only in elderly women but also in the young and middle aged female populations of western industrialised countries. In publications on the prevalence of urinary incontinence $\left(\mathbf{P}_{\mathrm{UI}}\right)$, the type of study population, definitions of urinary incontinence, and other research methodology applied differ and, consequently, prevalence figures are not consistently comparable. However, a $10-15^{\circ}{ }_{0} P_{U I}$ for age groups $20-60$ years seems a reasonable overall minimum estimate. ${ }^{1}$ In accordance with this, we have previously found the 1987 period $\mathrm{P}_{\mathrm{UI}}$ to be $17^{\circ}{ }_{\mathrm{o}}$ in a random population sample of Danish women aged 30-59 years. $^{2}$

In spite of the fact that much is known about the pathophysiology and the clinical features of urinary incontinence, documentation on its aetiology is scarce. Several factors may determine adult female $\mathrm{P}_{\mathrm{UI}}$, eg, age ${ }^{2}$ and health status. ${ }^{3}$ Moreover, in everyday medical practice pregnancy and childbirth are thought to be potent causes of urinary incontinence, but published studies investigating possible associations between pregnancy or childbirth and incontinence are rare and their findings seem mutually conflicting.

We have been able to identify only a few studies concerned with the prevalence of urinary incontinence, while none deals with incidence. Table I gives an overview of such published cross sectional studies on parity-indicating pregnancies and childbirths in the past-and $P_{U I}$ that present information sufficient for reanalysis for comparison of findings. The reanalyses had to be restricted to bivariate associations, as none of the publications present data stratified by possible confounding variables. Moreover, with the exception of the publication by Crist, ${ }^{4}$ they put forward no analytic results controlled for confounding variables such as age. Three of the four studies agree on the existence of a significantly positive association between parity and $P_{U I}$. The numbers published by Hørding ${ }^{5}$ leave room for a positive but insignificant relative risk, based on a very small number of nulliparous study subjects, in total 36.

In accordance with this general impression, Sommer ${ }^{7}$ found a highly significant association between the number of childbirths and $P_{U I}$. Reanalyses of two of the table I data sets ${ }^{4} 6$ by use of bivariate logistic regression sustain this hypothesis, yielding significant multiplicative risks (odds ratio, OR) of 1.2 and 1.6 per additional childbirth. However significant, these estimates are imprecise as the model fits are poor.

Other studies, researching social clients (5272 subjects aged 15-64 years), ${ }^{8}$ patients under a gynaecological health control programme ${ }^{9}$ (512 subjects aged 20-70 years), and members of a national association for retired persons ${ }^{10}$ (451 subjects, mean age 70-74 years), have presented findings that further strengthen the hypothesis of an association between parity and $P_{\mathrm{UI}}$. In contrast to this, neither Diokno et $a l^{3}$ nor Hagstad and Janson ${ }^{11}$ found any such association when investi- 
Table I Review of published reports concerning parity as a correlate of female urinary incontinence (UI) prevalence $\left(P_{U I}\right):$ publications presenting sufficient numbers for bivariate reanalysis. ${ }^{a}$

\begin{tabular}{|c|c|c|c|c|c|c|c|c|}
\hline \multirow[b]{2}{*}{$\begin{array}{l}\text { Authors, } \\
\text { year of } \\
\text { reference }\end{array}$} & \multirow[b]{2}{*}{$\begin{array}{l}\text { Country of } \\
\text { origin }\end{array}$} & \multicolumn{3}{|l|}{ Study population } & \multicolumn{4}{|l|}{$P_{U I}$} \\
\hline & & Type & Size & $\begin{array}{l}\text { Age } \\
\text { range } \\
\text { (years) }\end{array}$ & $\begin{array}{l}\text { Nulli- } \\
\text { parous } \\
o \\
o\end{array}$ & $\begin{array}{l}\text { Parous } \\
{ }_{o}\end{array}$ & $R R^{a}$ & $O R^{a}$ \\
\hline $\begin{array}{l}\text { Crist et al, } \\
1972^{4}\end{array}$ & USA & $\begin{array}{l}\text { Hospital patients, } \\
\text { health personnel, } \\
\text { students }\end{array}$ & 1008 & $16-63$ & 30.9 & $39 \cdot 0$ & $1 \cdot 3^{\star}$ & $1.2 \dagger$ \\
\hline $\begin{array}{l}\text { Hørdjing et al, } \\
1986^{5}\end{array}$ & Denmark & $\begin{array}{l}\text { Population } \\
\text { birth cohort }\end{array}$ & 522 & 45 & 13.9 & $20 \cdot 3$ & $1 \cdot 5$ & $\S$ \\
\hline Jolleys, $1988^{6}$ & $\begin{array}{l}\text { Great } \\
\text { Britain }\end{array}$ & $\begin{array}{l}\text { General practice } \\
\text { patients }\end{array}$ & 833 & (Adults) & $16 \cdot 6$ & $48 \cdot 0$ & $2 \cdot 9 \ddagger$ & $1.6 \ddagger$ \\
\hline $\begin{array}{l}\text { Sommer et al, } \\
1990^{7}\end{array}$ & Denmark & $\begin{array}{l}\text { Random } \\
\text { population sample }\end{array}$ & 414 & $20-79$ & $11 \cdot 7$ & $31 \cdot 8$ & $2 \cdot 7 \ddagger$ & 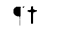 \\
\hline
\end{tabular}

$a^{a}$ Parous versus nulliparous women were reanalysed by use of relative risk (RR) and $\chi^{2}$ test with $\mathrm{d} \mathrm{f}=1$. Parity (number of deliveries) was reanalysed by use of logistic regression, yielding odds

ratio (OR) per additional childbirth, and likelihood ratio statistics.
\$ Not sufficient numbers for reanalysis; the association termed "not significant" in the report.

$\S$ Not sufficient numbers for reanalysis; the association termed "not significant" in the report.
A positive association is mentioned in the reference but without numerical evidence except the p value.

${ }_{\star}^{\mathrm{p}} \mathrm{p}<0.025 ; \uparrow \mathrm{p}<0.005 ; \neq \mathrm{p}<0.0005$.

gating female population samples of 1154 subjects aged 60 years and 1413 subjects aged $40-66$ years, respectively. However, with the exception of the studies by Diokno et $a l^{3}$ and Teasdale et $a l^{10}$ none gave any indication that confounder control had been performed. Thomas $e t a l^{8}$ present an illustrative figure on $P_{U I}$ stratified by age and parity which favours the hypothesis of a positive association.

As regards more specific questions, eg, concerning the possible existence of a certain threshold value of parity for $P_{U I}$ increase, two studies have indicated an especially high $P_{U I}$ in women with more than three childbirths. ${ }^{810}$ Bivariate reanalyses of table I data confirm this hypothesis only in part, since in Jolley's data ${ }^{6}$ such an association cannot be found, whereas in Crist's ${ }^{4}$ data women having given birth two or more times showed a substantially increased risk of having urinary incontinence after correction for the continuous number of deliveries $(O R=4.7, p<0.001$; model fit: $p>0.900)$. However, the study groups of all of the three reports indicating the existence of such threshold values are highly selective.

As concerns more specific delivery components, $P_{U I}$ has not been shown to correlate with type of delivery ${ }^{69}$ nor with duration of labour. ${ }^{9}$ On the other hand, Jolleys ${ }^{6}$ found an increased $P_{U I}$ risk associated with perineal suturing following delivery.

Consequently, the comprehensive picture based on published epidemiological studies

Table II Number and proportion of parous women, urinary incontinence (UI) prevalence $1987\left(P_{U I}, \%\right)$, and UI prevalence odds ratios (OR) with corresponding significant $p$ values, ${ }^{a}$ by clinical type of UI and present age in 2631 women, Aarhus, Denmark, 1988.

\begin{tabular}{|c|c|c|c|c|c|c|c|c|c|c|}
\hline \multirow{3}{*}{$\begin{array}{l}\text { Age } \\
\text { (years) }\end{array}$} & \multirow{2}{*}{\multicolumn{2}{|c|}{ Parous }} & \multicolumn{8}{|c|}{ Clinical type of $U I$} \\
\hline & & & \multicolumn{2}{|l|}{ All $U I$} & \multicolumn{2}{|l|}{ Stress UI } & \multicolumn{2}{|l|}{ Urge UI } & \multicolumn{2}{|c|}{$\begin{array}{l}\text { Mixed stress } \\
\text { and urge UI }\end{array}$} \\
\hline & $n$ & $\%$ & $P_{U I}(\%)$ & $O R$ & $P_{U I}(\%)$ & $O R$ & $P_{U I}(\%)$ & $O R$ & $P_{U I}(\%)$ & OR \\
\hline $\begin{array}{l}30-34 \\
35-39 \\
40-44 \\
45-49 \\
50-54 \\
55-59\end{array}$ & $\begin{array}{l}256 \\
319 \\
415 \\
318 \\
369 \\
377\end{array}$ & $\begin{array}{l}61 \cdot 7 \\
76 \cdot 0 \\
81 \cdot 7 \\
86 \cdot 9 \\
82 \cdot 9 \\
82 \cdot 1\end{array}$ & $\begin{array}{l}10 \cdot 4 \\
16 \cdot 2 \\
15.6 \\
24 \cdot 0 \\
20 \cdot 0 \\
17.9\end{array}$ & $\begin{array}{l}4.39 \\
1.6 \\
1.7 \\
1.1 \\
0.9 \\
1.3\end{array}$ & $\begin{array}{r}8.7 \\
13.6 \\
12.6 \\
21.6 \\
18.0 \\
15.7\end{array}$ & $\begin{array}{l}5 \cdot 5 \\
2.5 t \\
2 \cdot 4^{\star} \\
1.1 \\
1.0 \\
1.9\end{array}$ & $\begin{array}{r}5 \cdot 1 \\
8.6 \\
6.7 \\
12.6 \\
9.4 \\
10 \cdot 0\end{array}$ & $\begin{array}{l}2 \cdot 8 \\
1 \cdot 1 \\
0.9 \\
1.3 \\
1.0 \\
1.0\end{array}$ & $\begin{array}{l}4 \cdot 3 \\
6 \cdot 7 \\
5 \cdot 3 \\
0 \cdot 7 \\
8 \cdot 1 \\
8 \cdot 3\end{array}$ & $\begin{array}{l}3 \cdot 2^{\star} \\
1.5 \\
1.0 \\
1.4 \\
1.0 \\
1.9\end{array}$ \\
\hline Total & 2054 & $78 \cdot 6$ & $17 \cdot 1$ & $1.6^{c} \ddagger$ & $14 \cdot 8$ & $1.9^{c a}$ & $8 \cdot 6$ & $1 \cdot 2^{c}$ & $7 \cdot 1$ & $1.5^{c \star}$ \\
\hline $\begin{array}{l}30-44 \\
45-59\end{array}$ & $\begin{array}{r}990 \\
1069\end{array}$ & $\begin{array}{l}73 \cdot 7 \\
82 \cdot 6\end{array}$ & $\begin{array}{l}14 \cdot 1 \\
20 \cdot 2\end{array}$ & $\begin{array}{l}2 \cdot 3^{c} \\
1 \cdot 2\end{array}$ & $\begin{array}{l}11 \cdot 7 \\
18 \cdot 0\end{array}$ & $\begin{array}{l}3 \cdot 3 \S \\
1.3\end{array}$ & $\begin{array}{r}6 \cdot 8 \\
10 \cdot 5\end{array}$ & $\begin{array}{l}1 \cdot 4 \\
1 \cdot 1\end{array}$ & $\begin{array}{l}5.4 \\
8.9\end{array}$ & $\begin{array}{l}1 \cdot 7 \\
1 \cdot 4\end{array}$ \\
\hline Total & 2054 & $78 \cdot 6$ & $17 \cdot 1$ & $1.6^{c \ddagger}$ & $14 \cdot 8$ & $1.9^{c} \S$ & $8 \cdot 6$ & $1 \cdot 2^{c}$ & $7 \cdot 1$ & $1.5^{c \star}$ \\
\hline
\end{tabular}

$a_{\mathrm{p}<0.05}$, based on $\chi^{2}$ heterogenity tests (parous, yes/no) or logistic regression (number of childbirths).

Missing information on age: 18 women.

${ }^{c}$ Corrected for age ( 5 year and 15 year age groups) by logistic regression.

$\star_{p}<0.05 ; \dagger p<0.025 ; \ddagger p<0.001 ; \S p<0.0005 ; \uparrow p<0.0001$. remains one of mutually conflicting findings both concerning the overall question of the mere existence of a positive association between parity and $\mathrm{P}_{\mathrm{UI}}$, and also regarding more specific hypotheses such as, for example, certain parity threshold values.

The present report deals with data from a study on, among other things, determinants of the prevalence of urinary incontinence in an unselected random population sample of adult Danish females. ${ }^{2}$ The object of the present analysis was to penetrate further into the hypothesis that parity determines the prevalence of different clinical types of urinary incontinence, after correction for what we think would by now be a relevant set of confounding variables.

\section{Methods}

The material has been described previously. ${ }^{2}$ During January and February, 1988, the members of an age stratified cross sectional random sample of 3114 women, age 30-59 years, living in the municipality of Aarhus (total female population of the same age $=47702$ ), were mailed a self administered postal questionnaire. Nonrespondents were addressed two additional times. Finally, $2631(84.5 \%)$ responded, with a slight reduction by age, $\mathrm{OR}=0.93$ per five year group, $\mathrm{p}<0.025$ (multiple logistic regression estimate).

Among other things, the women were asked whether they had experienced involuntary loss of urine during the year 1987; whether it was generally provoked by physical stress or accompanied by a feeling of urge; whether they had ever given birth to a child; if so, how many times and when; what was their occupation as of 1987. A maximum of five childbirths were allowed for in the questionnaire, so that registered parity constitutes a minimum estimate.

The question regarding urinary incontinence during 1987 allows for period prevalence estimation, hereafter just termed "prevalence". By definition, prevalence is influenced by causative as well as sustaining mechanisms. Urinary incontinence is divided in four clinical categories: (1) all types of urinary incontinence together ("all UI"; prevalence 1987="all PUI"), (2) stress incontinence (prevalence 1987="stress PUI"); (3) urge incontinence (prevalence 1987="urge $P_{\text {UI"); } \text { and (4) mixed urge and stress incontinence }}$ (prevalence 1987="mixed PUI"). The classifications concerning stress and urge incontinence are concerned with provocative factors for urinary incontinence and are thus not mutually exclusive, ie, the category "stress UI" includes cases with urge incontinence and vice versa.

Approximately one third of the respondents were aged $30-39,40-49$, and 50-59 years, respectively. Fifty percent were white collar workers, $20.8 \%$ blue collar workers, and $29.2 \%$ had other occupations; $33.6 \%$ women had passed the menopause; $63.3 \%$ had been exposed to abdominal, gynaecological-obstetric, or urological surgery.

The statistical analysis applies $\chi^{2}$ tests for the $2 \times 2$ table, Pearson correlation and logistic regression. ${ }^{12} 13$ In tables IV and VII, odds ratios are presented with $95 \%$ confidence intervals in parentheses. All analyses were performed by one of the authors (AF). 
Results

URINARY INCONTINENCE AND CHILDBIRTH

Four hundred and fifty women $(17 \cdot 1 \%)$ had experienced some type of urinary incontinence during 1987 . The 1987 period prevalence of stress incontinence was $14.8 \%$, urge incontinence $8.6 \%$, and mixed stress and urge incontinence $7 \cdot 1 \%$. Among prevalent cases, more than $80^{\circ}{ }_{0}$ were provoked by physical stress.

Seventy eight percent of the women were parous and $21.4 \%$ nulliparous (table II). On average, each woman reported 1.7 childbirths, totalling 4552 births. The mean age at first childbirth was 24.4 years and at the second, third, fourth, and fifth births, $27 \cdot 2,29 \cdot 5,31 \cdot 4$, and $33 \cdot 7$ years, respectively. As expected, the proportion of parous women increased with increasing present age $(O R=1.2$ per 5 years, $p<0.0005)$. Accordingly, the number of childbirths was shown to be positively correlated to present age (Pearson's $r=0.25, \mathrm{p}<0.001)$ and negatively to age at first childbirth (Pearson's $r=-0.39, \mathrm{p}<0.001$ ), while there was no bivariate association between present age and age at first childbirth.

\section{CHILDBIRTH AS AN AETIOLOGICAL CORRELATE}

$\mathrm{P}_{\mathrm{UI}}$ was found to increase with present age in all four clinical types of urinary incontinence (eg, all clinical types: $O R=1.6$ per additional 5 years of age, $p<0.0001$ ) (table II). There were significant age corrected associations between being parous and $\mathrm{P}_{\mathrm{UI}}$. Significant bivariate associations were found in age groups below 45 years. Bivariately, all $P_{U I}$, stress $P_{U I}$, and mixed stress and urge $P_{U I}$ also depended on the number of childbirths (table III).

Furthermore, all types of $\mathrm{P}_{\mathrm{UI}}$ depended on menopausal state (all $P_{U I}$ : $O R=1.3, p<0.01$; stress $P_{U I}: O R=1.3, p<0.01$; urge $P_{U I}: O R=1.4$, $\mathrm{p}<0.05$; and mixed urge and stress $P_{U I}$ : OR 1.4, $\mathrm{p}<0.05)$; and exposure to abdominal, gynaecological-obstetric or urological surgery (all $P_{U I}: O R=2 \cdot 0, p<0.0000$; stress $P_{U I}: O R=2 \cdot 1$, $\mathrm{p}<0.0000$; urge $\mathrm{P}_{\mathrm{UI}}: \mathrm{OR}=1.6, \mathrm{p}<0.005$; mixed urge and stress $\left.P_{U I}: O R=1 \cdot 6, p<0.005\right)$. White collar workers showed a reduced risk of urge incontinence and mixed stress and urge incontinence compared to other occupations $(\mathrm{OR}=0.7, \mathrm{p}<0.05, \quad$ and $0.7, \quad \mathrm{p}<0.025$, respectively).

With respect to all women, multiple logistic regressions including correction for age, occupa-

Table III Number and proportion of parous women, urinary incontinence (UI) prevalence 1987 ( $P_{U I},{ }^{o}$ ) and significant ${ }^{a}$ UI prevalence odds ratios (OR) with corresponding $p$ values, by clinical type of UI and parity in 2631 women, Aarhus, Denmark, $1988^{a}$

\begin{tabular}{|c|c|c|c|c|c|c|c|c|c|c|c|}
\hline \multirow[b]{3}{*}{ Parity } & & & & \multicolumn{8}{|c|}{ Clinical type of UI } \\
\hline & & \multicolumn{2}{|c|}{ Delivered } & \multicolumn{2}{|l|}{ All UI } & \multicolumn{2}{|l|}{ Stress UI } & \multicolumn{2}{|l|}{ Urge UI } & \multicolumn{2}{|c|}{$\begin{array}{l}\text { Mixed stress } \\
\text { and urge UI }\end{array}$} \\
\hline & & $n$ & $\%$ & $P_{U I}(\%)$ & $O R$ & $P_{U I}\left({ }^{\circ}{ }_{0}\right)$ & $O R$ & $P_{U I}\left({ }^{o}{ }_{0}\right)$ & $O R$ & $P_{U I}(\%)$ & $O R$ \\
\hline Parous & $\begin{array}{l}\text { Yes } \\
\text { No }\end{array}$ & $\begin{array}{r}2059 \\
572\end{array}$ & $\begin{array}{l}78 \cdot 3 \\
21 \cdot 7\end{array}$ & $\begin{array}{l}18.6 \\
11.9\end{array}$ & $1 \cdot 7 \dagger$ & $\begin{array}{r}16.5 \\
8.7\end{array}$ & $2 \cdot 1 \neq$ & $\begin{array}{l}9 \cdot 0 \\
7 \cdot 0\end{array}$ & & $\begin{array}{l}7 \cdot 7 \\
4 \cdot 9\end{array}$ & $1 \cdot 6^{\star}$ \\
\hline Parity & $\begin{array}{l}0 \\
1 \\
2 \\
3 \\
4 \\
5\end{array}$ & $\begin{array}{r}572 \\
411 \\
1015 \\
457 \\
131 \\
45\end{array}$ & $\begin{array}{r}21 \cdot 7 \\
15 \cdot 6 \\
38 \cdot 6 \\
17 \cdot 4 \\
5 \cdot 0 \\
1 \cdot 7\end{array}$ & $\begin{array}{l}11.9 \\
17 \cdot 0 \\
16 \cdot 3 \\
23.2 \\
22.1 \\
26.7\end{array}$ & $1 \cdot 2 \ddagger$ & $\begin{array}{r}8 \cdot 7 \\
14 \cdot 6 \\
14 \cdot 4 \\
21 \cdot 7 \\
18 \cdot 3 \\
22 \cdot 2\end{array}$ & $1 \cdot 3 \ddagger$ & $\begin{array}{r}7.0 \\
8.8 \\
8.6 \\
9.8 \\
11.5 \\
6.7\end{array}$ & & $\begin{array}{l}4 \cdot 9 \\
7 \cdot 8 \\
7 \cdot 3 \\
8 \cdot 5 \\
9 \cdot 2 \\
4 \cdot 4\end{array}$ & \\
\hline
\end{tabular}

tion, menopause, and exposure to abdominal, gynaecological-obstetric or urological surgery, showed that all $P_{U I}$ and stress $P_{U I}$ were determined by the number of childbirths and, in regressions not including this, by being parous and having given birth three times or more (table IV). Neither urge nor mixed stress and urge $P_{U I}$

Table IV Prevalence odds ratios of adult female urinary incontinence (UI) by clinical type of UI and parity: significant ${ }^{\star}$ findings from multiple logistic regressions ${ }^{b}$ in 2631 women, Aarhus, Denmark, 1988.

$\begin{array}{ll}\text { Age group analysed, } & \text { Clinical type of UI } \\ \text { model, detcrminant } & \text { All UI Stress UI }\end{array}$
model, detcrminant Allinical type of UI All women, 30-59 years:

Model Ic

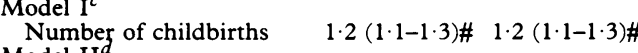
Model II

Parous (yes/no) $1.4(1.0-1.8)^{\star} 1.6(1.2-2.3) \S$ Three or more childbirths $1.4(1 \cdot 1-1 \cdot 8) \S \quad 1.4(1 \cdot 1-1 \cdot 8) \ddagger$

Subgroup 30-44 years:

Model $I^{c}$

Number of childbirths $1.3(1 \cdot 1-1 \cdot 5) \quad 1.4(1 \cdot 2-1 \cdot 6) \#$

Model II

Parous (yes/no)

$2 \cdot 1(1 \cdot 4-3 \cdot 2) \# 3 \cdot 0(1 \cdot 8-5 \cdot 1)$ \#

Subgroup 45-59 years:

Model II

Three or more childbirths $1.4(1.1-1.9) \dagger \quad 1.5(1.1-2.0) \dagger$

${ }^{a}$ With $95^{\circ}$ o confidence limits in brackets.

${ }^{b}$ Determinants: age (1987), exposure to abdominal, gynaecologic-obstetric or urologic surgery, menopause, occupacion parity (parous, yes/no; number of childbirths; at least given birth $x$ times, yes/no).

'Including the variable 'Number of childbirths'

${ }^{d}$ Excluding the variable 'Number of childbirths'

${ }^{\star} \mathrm{p}<0.05 ;+\mathrm{p}<0.025 ; \pm \mathrm{p}<0.01 ; \S \mathrm{p}<0.005 ; \quad \mathrm{p}<0.0005$; $\# p<0.0000$.

depended significantly on parity. Analysed separately, women aged 30-44 years showed increased all $P_{U I}$ and stress $P_{U I}$ conditional on being parous and conditional on the number of childbirths. Only women aged 45 years and over showed raised prevalences conditional on three or more childbirths.

In multiple logistic regressions, after correction for parity and surgery, all $P_{U I}$ and stress $P_{U I}$ both decreased with increasing age (both odds ratios $=0.96$ per year, $\mathrm{p}<0.025$ ).

Finally, aetiological fractions selected on the basis of the existence of bivariately significant odds ratios, thus excluding age groups above 44 years and urge incontinence, are shown in table $\mathrm{V}$. Because of decreasing odds ratios with increasing age, attributable risks also decreased with age. In women aged 30-34 years, three quarters of their stress $\mathrm{P}_{\mathrm{UI}}$ could be attributed to being parous, while less than half of the $P_{U I}$ in $40-44$ year old women could be explained by parity. In women aged 45 years and over, $12^{\circ}{ }_{0}$ of all $P_{U I}$ was attributed to three or more childbirths $(p<0.005)$, the effect being most obvious in women aged $45-49$ years.

Table $V$ Parity aetiological fractions $(\%,)^{a}$ of adult female urinary incontinence (UI) by age and clinical type of UI in 2631 women, Aarhus, Denmark, 1988.

$\frac{\text { Clincal type of UI }}{\text { All UI }}$

\begin{tabular}{llll} 
Age (years) & All UI & Stress UI & Mixed UI \\
\hline $30-34$ & $67 \ddagger$ & $74 \ddagger$ & $58^{\star}$ \\
$35-39$ & & $48 \dagger$ & \\
$40-44$ & & $46^{\star}$ & \\
$30-44$ & $49 \ddagger$ & $63 \ddagger$ &
\end{tabular}

${ }^{a}$ Aetiological fractions shown are selected based on bivariately significant UI prevalence odds ratios $(p<0.05)$ 
$P_{\text {UI }}$ ASSOCIATIONS WITH TIME AND AGE SPECIFICATIONS OF CHILDBIRTH

Among parous women, bivariate associations between age and time of childbirth and $P_{U I}$ were shown to be modest (table VI). In bivariate analyses, stress and mixed stress and urge $P_{U I}$ were shown to depend on the woman having given birth to a child during $1950-59$, and urge $\mathrm{P}_{\mathrm{UI}}$ on childbirth during 1970-79. Stress and mixed stress and urge $P_{U I}$ decreased over the decades of first childbirths. While no type of $P_{U I}$ was shown to be associated with age at first childbirth, all $P_{U I}$ increased with age at last childbirth. Urge and mixed stress and urge $P_{U_{I}}$ increased with the time since last birth.

In parous women taken as a whole group, multiple logistic regressions did not reveal any association between $\mathrm{P}_{\mathrm{UI}}$ and time or age specifications of parity, including time since last birth. However, in separate analyses of the two major age groups, women aged 30-44 years showed increased risks of all types of $P_{U I}$ with increasing age at last childbirth (table VII). In women aged 45 years and more, all $P_{U I}$ increased with parity, and stress $P_{U I}$ decreased with increasing age at first childbirth.

\section{Discussion}

Our findings suggest a strong relationship between parity and, as indicated by $\mathrm{P}_{\mathrm{UI}}$, the development and persistence of urinary incontinence, and particularly stress incontinence, in parous women. We found $\mathrm{P}_{\mathrm{UI}}$ to be high in parous women aged 30-44 years of age, and it increased with increasing parity. Associated with a parity of three or more, $P_{U}$ was raised especially in women aged 45 years and over. Moreover, in all age groups $P_{U I}$ was found to be associated with age at childbirth. No association was found with time since last childbirth, but the association between prevalent urinary incontinence and childbirth faded with increasing age. In the age group 30-44 years, more than half the prevalent stress incontinence could be attributed to parity. The substantial contribution of childbirth to urinary incontinence and/or its persistence indicated by these findings was underscored by the diminishing role of age in the presence of indicators of parity.

The present investigation may be compared to other studies performed with similar sampling techniques in cross sectional female populations of corresponding age. ${ }^{5711}$ Such studies have been found only for Scandinavian populations, showing comparably low levels of non-respondency. Moreover, our sample size exceeds the studies just mentioned by a factor two to five, which of course allows for more associations to emerge significantly.

As indicated by Mohide, ${ }^{14}$ the type of definition of urinary incontinence applied, as well as techniques for sampling and data collection, influence the empirical estimation of $P_{U I}$. Like most other studies on $P_{U I},{ }^{346-10}$ the present one is based on self administered postal questionnaires. Hørding et $a l^{5}$ and Hagstad and Janson ${ }^{11}$ collected their data by use of medical interview. Because of the possible introduction of interviewer influence on answers, this may be a source of differences in findings. Both publications present relatively low urinary incontinence prevalences while none of them report significant associations between incontinence and parity.

The present data set contains information on the study participants subjectively perceiving urinary incontinence as a hygienic and/or a social problem, in agreement with part of the definition of the International Continence Society (ICS). ${ }^{15}$ However relevant the ICS definition may be for
Table VI Number and proportion of women giving birth to a child, urinary incontinence (UI) prevalence 1987 $\left(P_{U I}, \%\right)$ and significant UI prevalence odds ratios $(O R)$ with corresponding $p$ values, by clinical type of UI and time (decade) of childbirth, age at childbirth, and duration (years) since last childbirth in 2059 parou women, Aarhus, Denmark, 1988.

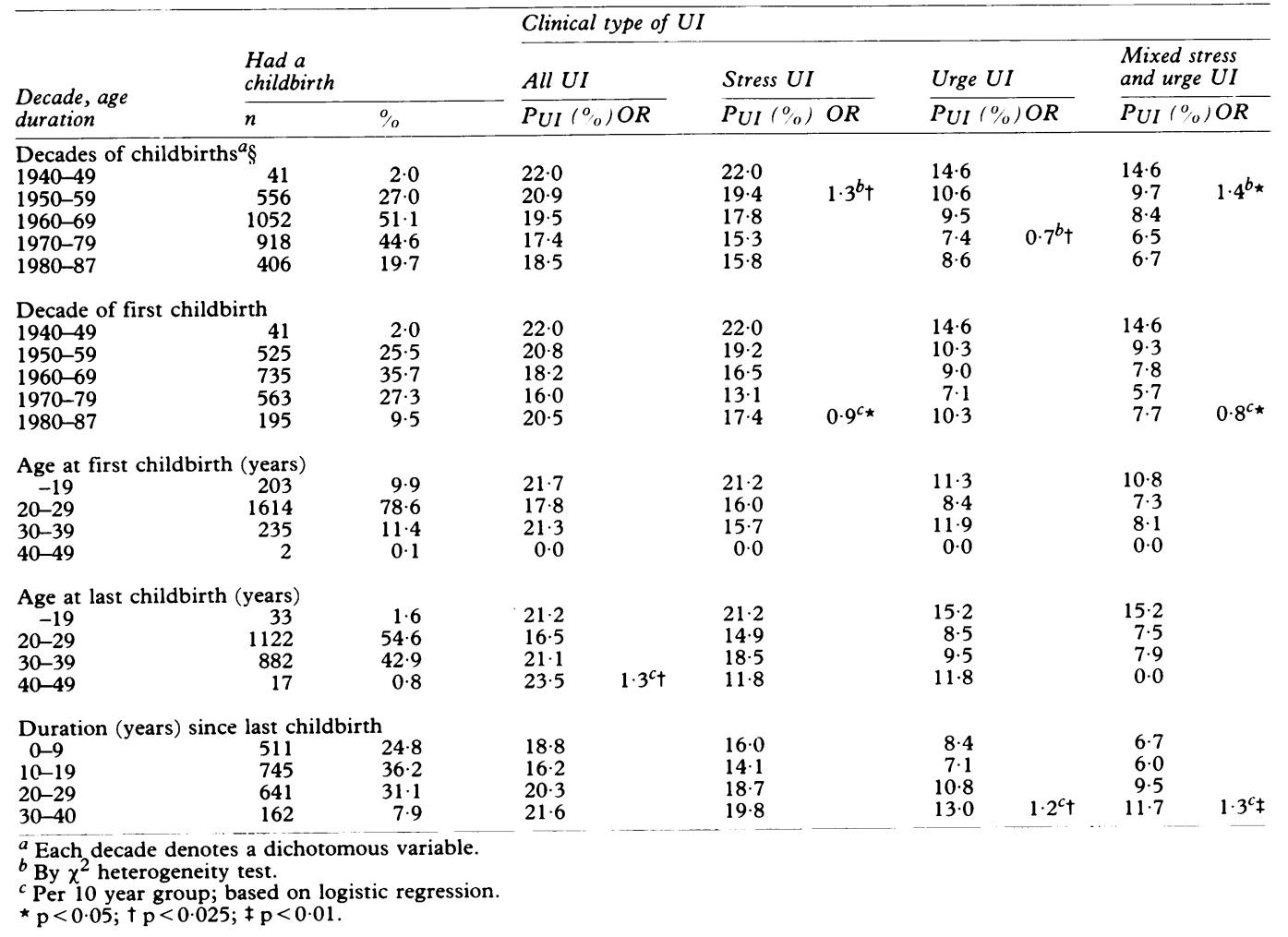


Table VII Prevalence odds ratios ${ }^{a}$ of adult female urinary incontinence (UI) by clinical type of $U I$ and parity: significant findings from multiple logistic regressions ${ }^{b}$ in 2059 parous women, Aarhus, Denmark, 1988.

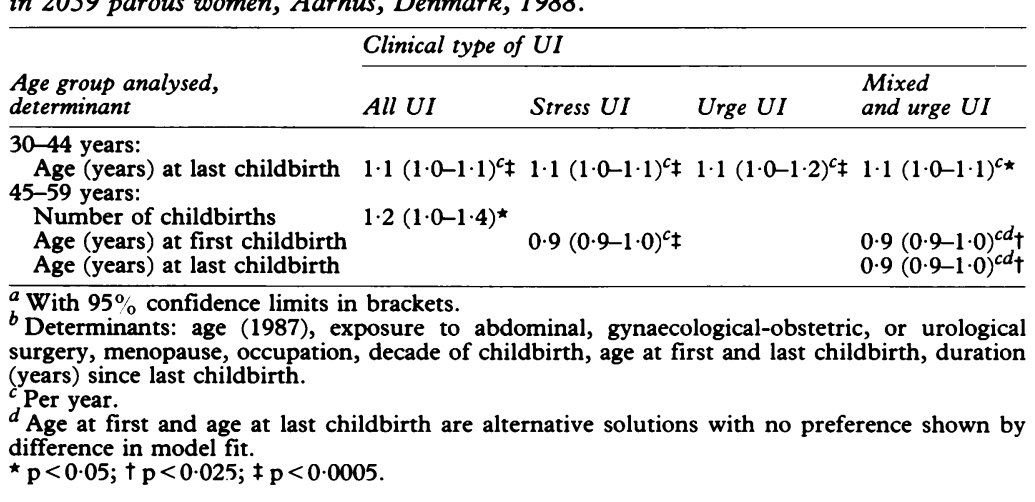

selection of patients for treatment in everyday medical practice, it is not necessarily fit for scientific research purposes. In the present analyses, based on considerations concerning the vagueness of such concepts as "social" and "hygienic", we chose to include all urinary incontinence reported by the women themselves, irrespective of whether it was considered a social or hygienic problem. In contrast to this, Hørding et $a l^{5}$ applied the hygienic and social criteria as perceived by the interviewer and maybe also by the interviewed. Their report provides no further details in this respect, but the impact may have been that of a differentiated information bias since parity, besides being a biomedical indicator, is also associated with social background and, consequently, with socially determined values and thresholds.

Some of the epidemiological studies cited differentiate clinical types of urinary incontinence, concentrating preferentially on stress incontinence, ${ }^{3-579}$ while others deal just with incontinence. ${ }^{681011}$ In both groups of studies, strong associations with parity have emerged. ${ }^{4-8} 10$ We found significant associations between parity and all urinary incontinence, but stress incontinence definitely revealed itself as the clinical type of incontinence of interest in this context.

This agrees with the most obvious pathophysiological explanation of urinary incontinence associated with parity, namely that it may be based on perineal muscular or neuromuscular dysfunction caused by childbirth. In a clinical neurophysiological study, Snooks et al ${ }^{16}$ found that most urinary incontinence following vaginal delivery was caused by injury not to the pelvic floor muscles themselves but to their innervation, most evident in multiparous women and in those who had experienced a prolonged second stage of labour or a forceps delivery. At five year follow up, occult disturbances of the pudendal innervation of the external anal sphincter persisted, eventually more marked with time since delivery. ${ }^{17}$ Comparable results were obtained by Swash, ${ }^{18}$ who furthermore concluded that the injury to the innervation of the pelvic floor is worsened by succeeding deliveries and is then exacerbated by repeated straining of stool with traction on the pelvic floor, leading to further stretch induced injury to the pudendal nerve.

This complies neatly with our finding of a definite trend in $P_{U I}$ with increasing parity, suggesting a cumulative effect of additional childbirths. However, at the same time damage to the pelvic floor caused by delivery may be subject to reparative processes, as illustrated by the decrease in relative risks with increasing age. Moreover, in women aged 45 years and over, only a parity of three or more was associated with $P_{U I}$, parallel to Teasdale's observation on elderly women. ${ }^{10}$ Accordingly, we hypothesised that $P_{U I}$ decreases with increasing time since last delivery, but this could not be demonstrated in our data (table VII). In parous women aged 45 years and over, we found $\mathrm{P}_{\mathrm{UI}}$ to be associated with age at first childbirth, suggesting that some ages are more vulnerable than others. This does not seem to have been documented previously.

In spite of the fact that the association between parity and urinary incontinence prevalence diminishes with age, it seems reasonable to suggest that neuromuscular damage to the pelvic floor caused by childbirth may persist, as shown for instance by the role of three or more childbirths in women aged 40 years and over (40-44 years: $P_{\mathrm{UI}}=15 \cdot 6^{\circ}{ }_{0}, \mathrm{OR}=1.49, \mathrm{p}<0.20 ; 45-49$ years: $P_{\text {UI }}=24.0^{\circ}{ }_{0}, O R=1.69, \mathrm{p}<0.05 ; 50-54$ years: $\mathrm{P}_{\mathrm{UI}}=20 \cdot 0^{\circ}{ }_{\mathrm{o}}, \mathrm{OR}=1.51, \mathrm{p}<0 \cdot 10 ; 55-59$ years: $\left.\mathrm{P}_{\mathrm{UI}}=17.9^{\circ}{ }_{0}, \quad \mathrm{OR}=1.46, \mathrm{p}<0.15\right)$. As the respondents reported childbirths between 40 and 44 years of age to be extremely rare, in total 18 out of 4552 births and none at all after the age of 43, the $P_{U I}$ increase after 39 years obviously has to be explained by a causative mechanism other than childbirth. ${ }^{19}$ We actually found $P_{U I}$ to decrease with age when simultanously corrected for parity and surgical experience.

As indicated by the finding by Jolleys on the role of perineal suturing, ${ }^{6}$ obstetric procedures may play a role in the aetiology of urinary incontinence. Among parous women we only found bivariate associations with decades of childbirth, indicating perhaps that major changes in the procedures and technology applied in the obstetric services may have played a part.

In order to penetrate causative mechanisms further, there remains a definite need for empirical standardisation and validation of research methodology, including the operational definition of urinary incontinence, followed by epidemiological follow up studies that enrol women, eg, during pregnancy or just after delivery and which include data on urinary incontinence reported by the women themselves as well as clinical and neurophysiological observations during and after pregnancy and childbirth.

\section{Conclusion}

Our findings support the hypothesis of pregnancy and childbirth being potent causes of urinary incontinence in adult females, as we found strong associations between indicators of parity and, as indicated by $P_{U I}$, the development and persistence of urinary incontinence, especially stress incontinence, in parous women. The effect is suggested to be cumulative and long lasting but subject to reparative processes that are to some extent successful.

The study was supported by the Danish Health Research Council, the Health Care Division of the 
Mölnlycke Co, the KabiVitrum Co, the Danish Urological Society (the Rahbek Foundation), and the research fund of the Aarhus County division of the Danish Medical Doctors' Association.

1 Herzog AR, Fultz NH. Prevalence and incidence of urinary incontinence in community-dwelling populations. $f \mathrm{Am}$ Geriatr Soc 1990; 38: 273-81.

2 Elving L, Foldspang A, Lam GW, Mommsen S. Descriptive epidemiology of urinary incontinence in 3100 women age 30-59. Scand 7 Urol Nephrol Suppl 1989; 125: 37-43.

3 Diokno AC, Brock BM, Herzog AR, Bromberg J. Medical correlates of urinary incontinence in the elderly. Urology 1990; 36: 129-38.

4 Crist T, Shingleton HM, Koch F, Koch GG. Stress incontinence and the nulliparous patient. Obstet Gynecol 1972; 40: 13-17.

5 Hørding U, Pedersen KH, Sidenius K, Hedegaard L. Urinary incontinence in 45-year-old women. Scand $\mathcal{F}$ Uro Nephrol 1986; 20: 183-6.

6 Jolleys JW. Reported prevalence of urinary incontinence in women in a general practice. $B M F$ 1988; 296: 1300-2.

7 Sommer P, Bauer T, Nielsen KK, et al. Voiding patterns and prevalence of incontinence in women. A questionnaire survey. $B r f$ Urol 1990; 66: 12-15.

8 Thomas TM, Plymat KR, Blannin J, et al. Prevalence of urinary incontinence. $B M 71980 ; 281$ : 1243-5.

9 Iosif $S$, Henriksson L, Ulmsten U. The frequency of disorders of the lower urinary tract, urinary incontinence in particular, as evaluated by a questionnaire survey in a gynecological health control population. Acta Obstet Gynecol Scand 1981; 60: 71-6.

10 Teasdale TA, Taffet GE, Luchi RJ, et al. Urinary incontinence in a community-residing elderly population. $\mathcal{F}$ Am Geriatr Soc 1988; 36: 600-6.

11 Hagstad A, Janson PO, The epidemiology of climacteric symptoms. Acta Obstet Gynecol Scand Suppl 1986; 134: $59-65$.

12 Kleinbaum DG, Kupper LL, Morgenstern H. Epidemiologic research. Principles and quantitative methods. London: Lifetime Learning Publications, 1982.

13 Armitage P, Berry G. Statistical methods in medical research. Oxford: Blackwell Scientific Publications, 1988.

14 Mohide EA. The prevalence and scope of urinary incontinence. Clin Geriatr Med 1986; 2: 639-55.

15 Abrams P, Blaivas JG, Stanton SL, et al. Standardisation of terminology of lower urinary tract function. Neurourol terminology of lower urinary

16 Snooks SJ, Setchell M, Swash M, et al. Injury to innervation of pelvic floor sphincter musculature in childbirth. Lancet 1984; ii: 546-50.

17 Snooks SJ, Swash M, Mathers SE, et al. Effects of vaginal delivery on the pelvic floor: a 5-year follow-up. Br $\mathcal{f}$ Surg 1990; 77: 1359-60.

18 Swash M, Snooks SJ, Henry MM. Unifying concept of pelvic floor disorders and incontinence. $\mathcal{F} R$ Soc Med 1985; 78: 906-11.

19 Mommsen S, Foldspang A, Elving L, Lam GW. Surgical history as a correlate to adult female urinary incontinence prevalence. $\mathrm{Br} \mathcal{F}$ Urol (in press). 